\title{
Chronic Myeloid Leukemia with Coagulopathy: About one Case and Review of the Literature
}

\author{
Beddou G*, Yahyaoui H, Skali H, Benjelloun I, Ait Ameur M, Chakour M
}

Department of Biological Hematology, Avicenne Military Hospital in Marrakech, Morocco

DOI: $10.36347 /$ simcr.2020.v08i01.018

| Received: 10.01.2020 | Accepted: 17.01.2020 | Published: 22.01.2020

*Corresponding author: Beddou Ghita

Abstract Case Report

Introduction: Consumption coagulopathy or disseminated intravascular coagulation (DIC) corresponds to uncontrolled activation of coagulation in an anatomically intact vascular network leading to fibrin deposition in the vasculature, organ dysfunction, and consumption of clotting factors and platelets, and life-threatening hemorrhage. This is an acute and severe pathological situation with a very unpleasant prognosis providing very high mortality. Materials and methods: The study was conducted on a complicated case of chronic myeloid leukemia (CML) with disseminated intravascular coagulation (DIC). Observation: We report a case of a 75-year-old patient followed for type II diabetes and dyslipidemia under treatment who presented with generalized fatigue and a history of left hypochondrium discomfort. The abdominal examination revealed a splenomegaly $(5 \mathrm{~cm}$ from the cost overhang). The rest of the clinical examination was without peculiarity. On investigation, he was found to have a major hyperleukocytosis at $111.5 \mathrm{G} / 1$ with a leukocyte count as follows: PNN at $95.89 \mathrm{G} / \mathrm{l}$, PNE at 1.115 G / 1, PNB at $0 \mathrm{G} / 1$, Lymphocytes at $11,15 \mathrm{G} / 1$ and monocytes at $3.345 \mathrm{G} / 1$. The hemoglobin level was $8.3 \mathrm{~g} / \mathrm{dl}$ with a VGM at $86 \mu 3$, a TCMH at 29pg and a CCMH at $32.3 \mathrm{~g} / \mathrm{dl}$. The reticulocyte count was around 28,960 element / mm3. The platelet count was $279 \mathrm{G} / \mathrm{L}$. The blood smear objectified the presence of a $43 \%$ myelemia made up of $20 \%$ of myelocytes and $23 \%$ of metamyelocytes with a rate of circulating blasts of $9 \%$. A myelogram was performed one day after had objectified a very rich marrow with the presence of many megakaryocytes and major hyperplasia of the granular line at $86 \%$ is subject to compliance with the maturation pyramid without significant hiatus. The spinal cord blast rate was $10 \%$. The rate of basophils at $3 \%$ and eosinophils also at $3 \%$. At the end of the hematological exploration previously mentioned, a chronic myeloproliferative syndrome was mentioned; more precisely, chronic myeloid leukemia in the accelerated phase. The karyotype was in progress and a search for the BCR-ABL transcript returned $86 \%$ positive. The patient was put on medical treatment based on hydroxyurea, imatinib at a dose of $400 \mathrm{mg} /$ day and allopurinol and colchicine. Two weeks later, the evolution was marked by a worsening of his general condition made of fever at 38.5 and of an extensive mucocutaneous hemorrhagic syndrome. An emergency assessment had found: CRP at $294 \mathrm{mg} / 1$, VS at $92 \mathrm{~mm}$ at the 1st hour, PAL at $210 \mathrm{IU} / 1$, GGT at $177 \mathrm{IU} / 1$, with a hemostasis assessment objectifying an incoagulable plasma for the functional coagulation tests (quick time and partial thromboplastin time with activator outside of measurement ranges). Paradoxically, the fibrinogen level measured by the Von Glauss technique also exceeded the measurement range (rate> maximum), and the D-dimers had a value of $1.54 \mu \mathrm{g} / \mathrm{l}$. The diagnosis of consumption coagulopathy aggravating CML in this patient was made. She was immediately put into intensive care for the treatment of her DIC and supportive care. The acute renal failure set in, necessitating a hemodialysis session, but the patient died directly at the end of this session. Conclusion: The association of a DIC with a chronic myeloproliferative syndrome, namely CML remains a rare entity in comparison with the data in the literature except under the conditions of use of cytoreductive chemotherapy. The mechanism of the occurrence of this DIC in this particular context requires a more in-depth examination and a detailed study of each parameter influencing coagulopathy.

Keywords: CML, DIC, Imatinib, Coagulopathy.

Copyright @ 2020: This is an open-access article distributed under the terms of the Creative Commons Attribution license which permits unrestricted use, distribution, and reproduction in any medium for non-commercial use (NonCommercial, or CC-BY-NC) provided the original author and source are credited.

\section{INTRODUCTION}

Consumption coagulopathy or disseminated intravascular coagulation (DIC) corresponds to uncontrolled activation of coagulation in an anatomically intact vascular network leading to fibrin deposition in the vasculature, organ dysfunction, and consumption of clotting factors and platelets, and life- 
threatening hemorrhage [1]. This is an acute and severe pathological situation with a very unpleasant prognosis providing very high mortality. The association of a DIC with a chronic myeloproliferative syndrome, namely chronic myeloid leukemia (CML) remains a rare entity compared to the data in the literature.

DIC is generally correlated with many pathological situations in which they are the cause. Pregnancy circumstances, mainly bacterial infections, envenomation, surgical contexts, acute intravascular hemolysis, and malignant diseases remain the most frequent etiologies.

Among the malignant pathologies, acute leukemia, in particular, the acute promyelocytic leukemia which constitutes the malignant hemopathy most incriminated in the occurrence of a DIC in the acute phase of the disease. Other "glandular" cancers can induce a coagulopathy of consumption especially at the metastatic stage the disease evolution [1].

The association of a DIC with CML remains a rare entity in comparison with the data in the literature except under the conditions of the use of cytoreductive chemotherapy [2]. This brings us back to evoking this rare clinical situation through our observation and through some data from the literature to draw the attention of clinicians to the probability of the occurrence of this situation for possible prevention or, failing that, rapid management and adequate.

\section{ObServation}

We report a case of a 75-year-old patient with type II diabetes and dyslipidemia under treatment who consults in clinical hematology for generalized fatigue with and a history of left hypochondrium discomfort. The abdominal examination revealed a splenomegaly. On investigation, he was found to have a major hyperleukocytosis on a blood count done 2 days previously prescribed by a general practitioner.

The history of the disease goes back to 3 months marked by a gout attack made of edema of the left big toe with a painful crisis, a feeling of heaviness of the left hypochondrium, the whole evolving in a context of conservation of the general state.

The clinical examination found a tired, hemodynamically stable patient with a WHO (world health organization) grade performance index of 3 . Clinical splenomegaly was found $(5 \mathrm{~cm}$ from the cost overhang). The rest of the clinical examination was without peculiarity.

A blood cell count (made in Sysmex Xt 1800i machine) was then requested having objectified a major Hyperleukocytosis at $111.5 \mathrm{G} / 1$ with a formula made as follows: PNN at 95.89 G / 1, PNE at $1.115 \mathrm{G} / \mathrm{1}$, PNB at $0 \mathrm{G} / 1$, Lymphocytes at $11.15 \mathrm{G} / 1$ and monocytes at $3.345 \mathrm{G} / 1$.

The hemoglobin level was $8.3 \mathrm{~g} / \mathrm{dl}$ with a VGM at $86 \mu 3$, a TCMH at 29pg and a CCMH at $32.3 \mathrm{~g}$ / d1. The reticulocyte count was around 28,960 element / mm3. The platelet count was $279 \mathrm{G} \mathrm{/} \mathrm{L.} \mathrm{The}$ automaton's alarms are divided into Blasts, immature granulocytes, deviation to the left of the dill formula and atypical lymphocytes.

The blood smear objectified the presence of a $43 \%$ myelemia made up of $20 \%$ of myelocytes and $23 \%$ of metamyelocytes. A rate of circulating blasts of $9 \%$ was found.

Regarding qualitative anomalies; there were no signs of dysgranulopoiesis or an excess of basophils or eosinophils. On the other hand, many signs of dyserythropoiesis have been found, mainly in the form of anisopoikylocytosis and dacryocytes.

A myelogram was performed one day after had objectified a very rich marrow with the presence of many megakaryocytes and major hyperplasia of the granular line at $86 \%$ being subject to compliance with the maturation pyramid without significant hiatus. The rate of blasts was $10 \%$. The rate of basophils at $3 \%$ and eosinophils also at $3 \%$.

At the end of the hematological exploration previously mentioned, a chronic myeloproliferative syndrome was mentioned; more precisely, CML in the accelerated phase. And an additional assessment was carried out: Blood uric acid at $102 \mathrm{mg} / \mathrm{l}$, Creatinine at $11.2 \mathrm{mg} / 1$, Urea at $0.6 \mathrm{~g} / 1$, ASAT at $60 \mathrm{IU} / 1$, ALAT at $20 \mathrm{IU} / 1$, as well as negative hepatitis and retroviral serologies.

The karyotype was in progress and a search for the BCR-ABL transcript returned $86 \%$ positive. An abdominal ultrasound had found homogeneous splenomegaly measuring $14.7 \mathrm{~cm}$ with fatty liver.

Meanwhile (on the 4th day after the first consultation), the patient was put on medical treatment based on hydroxyurea, imatinib at a dose of 400mg / day and allopurinol and colchicine.

Two weeks later, the evolution was marked by a worsening of his general condition made of fever at 38.5 and of an extensive mucocutaneous hemorrhagic syndrome.

An emergency assessment had found: CRP at $294 \mathrm{mg} / \mathrm{l}$, VS at $92 \mathrm{~mm}$ at the 1st hour, PAL at $210 \mathrm{IU}$ / 1, GGT at $177 \mathrm{IU} / 1$

Electrophoresis of the proteins in favor of an inflammatory syndrome with hypoalbuminemia and 
hypergammaglobulinemia with restriction of heterogeneity.

A hemostasis assessment had objectified incoagulable plasma for the functional coagulation tests (quick time and partial thromboplastin time with activator outside of measurement ranges).

Paradoxically, the fibrinogen level measured by the Von Glauss technique also exceeded the measurement range (rate> maximum), and the D-dimers had a value of $1.54 \mu \mathrm{g} / 1$.

The diagnosis of consumption coagulopathy aggravating CML in this patient was made. She was immediately put into intensive care for the treatment of her DIC and supportive care.

The acute renal failure set in, necessitating a hemodialysis session, but the patient died directly at the end of this session.

\section{DISCUSSION}

DIC is the result of excessive and inappropriate activation of the hemostatic process. Its pathological activators are only partially known [1]. Procoagulant, anticoagulant and fibrinolytic factors are consumed [2]. Circulating thrombin also causes platelet activation, which further worsens the prothrombotic state. Consumption of platelets leads to thrombocytopenia. If fibrinolytic activation or the consumption of clotting factors and platelets dominate, bleeding may occur. This consequence is seen, for example, in acute promyelocytic leukemia due to the synthesis of plasminogen activators by leukemia cells.

This is not commonly seen in chronic myeloid leukemia, and very few studies have reported on it. The occurrence of such a dramatic situation can theoretically be linked to treatment. Indeed our patient was on imatinib which is an inhibitor of the tyrosine kinase activity of BCR-ABL successfully used in chronic myeloid leukemia, but it also inhibits other traditional knowledge, such as PDGF-r and c-KIT [3, 4]. Its hematological toxicity is rare and has been linked to myelosuppression [5] but however studies have shown that a large proportion of patients with CML $(85 \%)$ have patterns of platelet dysfunction by impaired induced platelet aggregation by defection of the cofactor ristocetin [6]. In fact, the positively charged ristocetin cofactor binds to the surface of the platelets by its action on the phenolic group and reduces its negative charge and therefore allows closer contact between the platelets, which allows the von Willebrand factor to fill the platelets and produce agglutination. Imatinib can modify the spatial conformation of the phenolic group as it can occupy binding sites on the surface of platelets and induce a decrease in platelet aggregation.
In addition, since the ristocetin cofactor binds to platelets, the decrease in the number of platelets after treatment with imatinib may be another explanation for the induced platelet aggregation. However, these hypotheses must be confirmed by other in vitro studies $[7,8]$. In addition, imatinib can be responsible for hemolytic anemia of autoimmune origin which will worsen the clinical picture. However, our patient was on imatinib for a short time (15 days) so her accountability is questionable.

Patients suffering from chronic myeloid leukemia have a thrombopathy site by reduction of platelet aggregation in collagen, in ADP and epinephrine with the presence of a defect in platelet production following a storage pool disorder [9, 10] responsible for but nevertheless these patients can thrombose [11]. Indeed thromboses are a major cause of morbidity/mortality in chronic myeloproliferative syndromes, [12] they can occur in unusual anatomical sites, such as venous splanchnic thrombosis or thrombosis of the cerebral sinus [13]. About $40 \%$ of patients have arterial or venous thrombosis at the time of diagnosis, while 8 to $19 \%$ present this latter under treatment $[14,15]$. The risk factors for the development of thrombosis in patients with PMS are multifactorial; they include environmental factors, host-related factors such as our patient who is known to be diabetic and dyslipidemic, as well as genetic factors, in particular, the presence of the JAK2 V617F mutation [16] which was not made in our situation.

These different factors can explain our patient's situation, but more studies are needed to better explain this rare situation.

\section{CONCLUSION}

We report a rare case of chronic myeloid leukemia complicated by disseminated intravascular coagulation. The mechanism of the occurrence of this DIC in this particular context requires a more in-depth examination and a detailed study of each parameter influencing coagulopathy.

\section{RÉFÉRENCES}

1. Bakhtiari K, Meijers JC, de Jonge E, Levi M. Prospective validation of the International Society of Thrombosis and Haemostasis scoring system for disseminated intravascular coagulation. Crit Care Med. 2004; 32 (12) : 2416-21.

2. Druker BJ, Tamura S, Buchdunger E, Ohno S, Segal GM, Fanning S, Zimmermann J, Lydon NB. Effects of a selective inhibitor of the Abl tyrosine kinase on the growth of BCR-ABL positive cells. Nat Med. 1996;2:561-566.

3. Schafer AI. Bleeding and thrombosis in myeloproliferative disorders. Blood. 1984;64:1-12.

4. Buchdunger E, Cioffi CL, Law N, Stover D, OhnoJones S, Druker BJ, Lydon NB. Abl protein- 
tyrosine kinase inhibitor STI571 inhibits in vitro signal transduction mediated by c-kit and plateletderived growth factor receptors. J Pharmacol Exp Ther. 2000;295:139-145.

5. Druker BJ, Lydon NB. Lessons learned from the development of an Abl tyrosine kinase inhibitor for chronic myelogenous leukemia. J Clin Invest. 2000;105:3-7.

6. Quintas-Cardama A, Han X, Kantarjian H, Cortes J. Tyrosine kinase inhibitorinduced platelet dysfunction in patients with chronic myeloid leukemia. Blood. 2009;114: 261-263.

7. Hensley ML, Ford JM. Imatinib treatment: specific issues related to safety, fertility, and pregnancy. Semin Hematol. 2003;40:21-25.

8. Heinrich MC, Griffith DJ, Druker BJ, Wait CL, Ott KA, Zigler AJ. Inhibition of c-kit receptor tyrosine kinase activity by STI571, a selective tyrosine kinase inhibitor. Blood. 2000;96:925-932.

9. Manoharan A, Gemmell R, Brighton T, Dunkley S, Lopez K, Kyle P. Thrombosis and bleeding in myeloproliferative disorders: identification of atrisk patients with whole blood platelet aggregation studies. Br J Haematol. 1999;105:618-625.

10. Agis H, Jaeger E, Doninger B, Sillaber C, Marosi C, Drach J, Schwarzinger I, Valent P, Oehler L. In vivo effects of imatinib mesylate on human haematopoietic progenitor cells. Eur J Clin Invest. 2006;36:402-408.

11. Kattlove HE, Gomez MH. Studies on the mechanism of ristocetin-induced platelet aggregation. Blood. 1975;45:91-96.

12. Wehmeier A, Schneider W. Megakaryocytes and platelets as the main cause for vascular events in chronic myeloproliferative disorders. Hamostaseologie. 1996;16:151-163.

13. Barbui T, Bassan R, Viero P, Cortelazzo S, Dini E. Platelet function after busulfan in chronic myeloproliferative disorders. Haematologica. 1983;68:469-477.

14. Appel S, Balabanov S, Brümmendorf TM, Brossart P. Effects of imatinib on normal hematopoiesis and immune activation. Stem Cells. 2005;23:10821088.

15. Wehmeier A, Scharf RE, Fricke S, Schneider W. A prospective study of hemostatic parameters in relation to the clinical course of myeloproliferative disorders. Eur J Haematol. 1990;45:191-197.

16. Coller BS, Gralnick HR. Studies on the mechanism of ristocetin-induced platelet agglutination. Effects of structural modification of ristocetin and vancomycin. J Clin Invest. 1977;60:302-312. 